\title{
Experimental Administration of Estradiol on the Colonization of Lactobacillus fermentum and Escherichia coli in the Urogenital Tract of Mice
}

\author{
Clara Silva de Ruiz, ${ }^{a}$ Maria del Rosario Rey, ${ }^{a}$ Aida Pesce de Ruiz Holgado, ${ }^{a, b}$ and \\ María Elena NADER-MACÍAS *,b \\ Facultad de Bioquímica, Química y Farmacia, Universidad Nacional de Tucumán ${ }^{a}$ and Centro de Referencia para \\ Lactobacilos (CERELA), ${ }^{b}$ Chacabuco 145, Tucumán, 4000, Argentina. \\ Received June 5, 2000; accepted October 31, 2000
}

\begin{abstract}
The effect of estrogen on the microbial colonization of the urogenital tract is widely discussed, mainly in regard to women with a high incidence of Urinary Tract Infections (UTI). The aim of this work was to study the effect of estradiol on the microbial colonization of lactobacilli and $E$. coli in mice. Female BALB/c mice were intramuscularly (i.m.) treated with $\beta$-estradiol (one or three doses). The next day, $L$. fermentum was inoculated intraurethrally with three doses of $10^{7} \mathrm{CFU}$ (Colony Forming Units). Later, mice were challenged with uropathogenic $E$. coli $\left(1 \times 10^{8} \mathrm{CFU}\right)$. The hormone levels in sera increased to values 10 times higher than in control animals. Increased differentiation of desquamated vaginal cells and keratinization of the vaginal surface were also observed. The hormonal treatment produced an increased $E$. coli colonization in the whole tract and a higher level of $L$. fermentum in kidneys on the 6th day. In mice treated with hormones and lactobacilli, one dose of estradiol was enough to protect animals against the challenge with $E$. coli. Three doses of estradiol produced a more pronounced protection with a lower number of $E$. coli. No histological modifications were produced by $L$. fermentum, while lymphocytic proliferation at submucosal level was observed in $E$. coli-challenged animals.
\end{abstract}

Key words Lactobacillus fermentum protection; uropathogenic Escherichia coli; probiotics; estradiol treatment; urogenital tract

The physiological condition of the urogenital tract changes during the life of different animals or humans, altering the normal microbial flora. ${ }^{1)}$ The number and species of bacterial populations depends on the stage of human life: premenarche, menarche, menstrual cycle, active reproductive cycle, or menopause. There is not much knowledge about the microbiological implications of the steroid-hormonal effect on the urogenital tract. Different characteristics can be influenced by hormones involved in the maintenance of the micro ecosystem. ${ }^{2)}$ The first is the vaginal epithelium that represents a system with constant cellular renovation. Cellular maturation, width of surface layer, and cell desquamation depend on the estrogenic stimulation period ${ }^{1)}$ in which the cells are divided. The second one is the microbial flora itself. The concept that the urogenital tract is colonized only by lactobacilli has been modified, particularly by those researchers who isolated anaerobic microorganisms, describing a diversity of microbial species. ${ }^{3,4)}$ The third aspect to be considered is the complexity of interactions between host-microorganisms and endogenous and exogenous species which can be, in turn, antagonistic or synergistic. ${ }^{1)}$

In a previous paper, an experimental model to study the protective and preventive effect of lactobacilli in the urogenital tract of mice was set up, ${ }^{5)}$ and the antibiotic effect on the colonization kinetics of both $L$. fementum and uropathogenic E. coli was studied. ${ }^{6}$ L. fermentum was intraurethrally inoculated as agarose beads, and E. coli as a suspension. The aim of the present work was to study the effect of estradiol on the kinetics of colonization of both groups of microorganisms, and the histological modifications produced by them.

\section{MATERIALS AND METHODS}

Microorganisms L. fermentum CRL 1058 was isolated from the vagina of BALB/c mice, as described before. ${ }^{7)} E$. coli was isolated from the infected urinary tract of adult women and identified by biochemical tests according to Orskov. ${ }^{8)}$ The latter strain was uropathogenic, because it possessed type P fimbriae and produced hemolysins, and also showed pyelonephritogenic effects when subjected to a hemagglutination test, as tested in mice. ${ }^{9)}$

Culture Media and Growth Conditions Media, lactobacilli culture conditions, and the preparation of microscopic agarose beads for intra-urethral administration were described previously. ${ }^{10)}$ Uropathogenic strains were grown in either Brain Heart Infusion (BHI) supplemented with $0.5 \%$ yeast extract, or LAPTg broth. ${ }^{11)}$ Not more than three-fold subcultures were performed in order to avoid changes in adhesion properties. Microorganisms were harvested by centrifugation, washed twice with phosphate buffer saline (PBS) pH 7.0 and suspended in $0.5 \%$ peptone-water. For intra-urethral inoculation of pathogens, suspensions of microorganisms were prepared in $0.5 \%$ peptone-water. Microorganism concentrations used are indicated in each experiment.

Animals Two-month-old female BALB/c mice from the inbreed colony of the Instituto de Microbiología at the Universidad Nacional de Tucumán were used throughout the entire experiment. Animals were housed in plastic cages, fed $a d$ libitum, keeping their environmental conditions constant. Each experiment was carried out with groups of $20-25$ mice. The CERELA (Centro de Referencia para Lactobacilos) Committee of Ethics approved the protocol used for animal studies.

Estrogenic Stimulation and Pathogen Challenge Estrogenic stimulation was performed by intramuscular (i.m.) inoculation of one or three doses of $0.5 \mathrm{mg}$ estradiol valerate (Progynon Depot. Schering Laboratories). The hormone was inoculated $48 \mathrm{~h}$ before inoculation with $L$. fermentum $\mathrm{CRL}$ 
1058 (three doses of $1.5 \times 10^{8} \mathrm{CFU}$ or $2.0 \times 10^{8} \mathrm{CFU}$ where indicated) and/or E. coli (one dose of $1.0 \times 10^{7} \mathrm{CFU}$ or $1.0 \times$ $10^{8} \mathrm{CFU}$ where indicated).

Microorganism Inoculation Mice were anaesthetized with sodium pentobarbital before intra urethral inoculation of $0.05 \mathrm{ml}$ of $L$. fermentum included in agarose beads. A plastic catheter coupled to a syringe was used for this purpose. Uropathogenic strains were inoculated in suspensions of $0.05 \mathrm{ml}$. After each inoculation animals were returned to their cages.

Doses are indicated with the results of each experiment, since most of them were different for experimental purposes. None of them, however, were effective, because the minimum infective dose for the pathogens was $10^{3} \mathrm{CFU}$. Lactobacilli administration was higher than $10^{5} \mathrm{CFU}$, which had been previously determined as the minimum concentration able to colonize. ${ }^{10)}$

The scheme indicating the doses, the time required, and the sequence of inoculation is shown in each of the figures.

Quantification of Serum Estriol Mice were bled from the retro-orbital venous plexus before being sacrificed. Serum was separated by centrifugation and frozen at $-20^{\circ} \mathrm{C}$. Quantitative determination of estriol was performed by using Microplate Enzyme Immunoassays (IMS System Abbot Laboratories, U.S.A.).

Vaginal Samples Vaginal washing was carried out with $50 \mu \mathrm{l}$ saline solution by using a syringe with a canule, aspirating the liquid. The samples were processed for the following studies: direct Gram staining, vaginal cytology, and culture in selective media.

Cytological Studies To study the cytological modifications, extended slides were fixed in $96 \%$ ethanol for $10 \mathrm{~min}$, and later stained with Papanicolaou technique. ${ }^{12)}$ The slides were observed with light microscopy; 200 cells were counted, and the different cellular types were differentiated. The basis of the technique is that the staining process is performed by the polychromatic action of a mixture of cationic, anionic and amphoteric stains. Each layer of pavement stratified epithelia produces a gradual range of colors, from intense green in the basal layer, to light orange in the superficial layer. The technique includes hydration with decreasing alcohols strengths $(80 \%-70 \%-50 \%)$, later staining with diluted Harris hematoxylin. Then a current dehydration with increasing alcohols strengths $(50 \%-70 \%-80 \%-96 \%)$, staining with G6 Orange, washing with $96^{\circ}$ ethanol, staining with 50 eosin azur, washing first three times with $96 \%$ alcohol, once with absolute ethylic alcohol, twice with xylol and then mounted with Canada balsam.

Gram Staining Gram staining was performed in vaginal wash, according to standard techniques.

Histological Studies The organs of the urogenital tract were aseptically removed. Kidney, ureter, bladder, urethra and vagina were fixed in $10 \%$ formaldehyde for $24 \mathrm{~h}$. Dehydration was accomplished by increasing ethanol $(70 \%-$ $80 \%-96 \%-100 \%$ ), clearing with xylene, and then they were embedded in paraffin. A Slipper microtome was used to cut the organs into $5 \mu \mathrm{m}$ slices. The slices were stained with hematoxylin-eosin, the paraffin removed and the slices moisturized with xylene. After treatement with decreasing alcohol strenghts $(100 \%-96 \%-70 \%-50 \%)$, the slices were stained with diluted Erlich hematoxylin, then with alcoholic eosin, dehydrated, and then mounted with Canada balsam. Histological changes were observed under a light microscope.

Bacterial Counts in Tissue Homogenates Animals were sacrificed by cervical dislocation. Their organs (urethra, bladder, ureters and kidneys) were removed aseptically, placed in $0.5 \%$ peptone water and homogenized with a Teflon pestle. Dilutions were made and the samples were plated on LBS-agar (Lactobacillus Selection Agar- Hi Media- India) in duplicate ${ }^{13)}$ and with a differential medium for Gram-negative bacilli (Mc Conkey agar-Merck-Germany). Plates were incubated for $48-72 \mathrm{~h}$. Viable cell counts were made for each organ. Results are expressed as the means \pm standard deviation (S.D.) of the data obtained from three to four animals.

\section{RESULTS}

Serum Estradiol Determination The animals were sacrificed on days 2, 10 and 15 after estradiol inoculation. The results obtained are shown in Table 1. An increased level of the hormone on day 2 and 10, with values always higher than those of control mice, was observed.

Vaginal Cytological Modifications Quantification of the different cell types obtained from the vaginal cytological studies are given in Fig. 1. Figure 1a shows the surface and intermediate epithelial cells obtained on different days from non-treated animals. When $\beta$-estradiol was injected $(0.5 \mathrm{mg})$, the cell pattern became completely different, showing an increase in the percentage of surface epithelial cells, while the intermediate cells decreased very quickly, reflecting the effect of estradiol on the differentiation of the vaginal epithelium cells (Fig. 1b). The different cells counted in the experiment are shown in Fig. 1c, and keratinization of the vaginal surface due to estrogen treatment is shown in Fig. 1d.

Quantification of Microorganisms in the Organs. Effect of 1 and 3 Doses of Estradiol on the Kinetics of $L$. fermentum Colonization Estradiol treatment with both one and three doses of $0.5 \mathrm{mg}$ produced an increase in lactobacilli colonization in the kidney. One dose produced a colonization of $10^{6} \mathrm{CFU} /$ organ in kidney on days 2 and 3 (Fig. 2a). With three doses of $0.5 \mathrm{mg}$ the number of lactobacilli in bladder and kidney first increased to values of $10^{6} \mathrm{CFU} /$ organ on day 2 post-challenge, disappearing completely on day 6 (Fig. 2b).

Effect of 1 and 3 Doses of Estradiol on the Kinetics of E. coli Colonization One dose of estradiol increased the levels of E. coli as early as day 2 after the challenge, with values higher than those of control mice without hormone inoculation. On days 3 and 6 there were statistically significant differences between mice with or without estradiol treatment (Fig. 3a). With 3 doses of estradiol, the number of $E$. coli de-

Table 1. Levels of Estradiol in the Serum of Animals Inoculated i.m. with $0.5 \mathrm{mg} 17-\beta$-Estradiol

\begin{tabular}{cc}
\hline \hline Days post-inoculation & Serum Estradiol $(\mu \mathrm{g} / \mathrm{ml})^{a)}$ \\
\hline 2 & 6.0 \\
10 & $1.95-3.0$ \\
15 & 3.0 \\
control & $0.1-0.4$
\end{tabular}

a) Serum estradiol was determined by the ELISA method, as described in the text. 
1a. Control mice

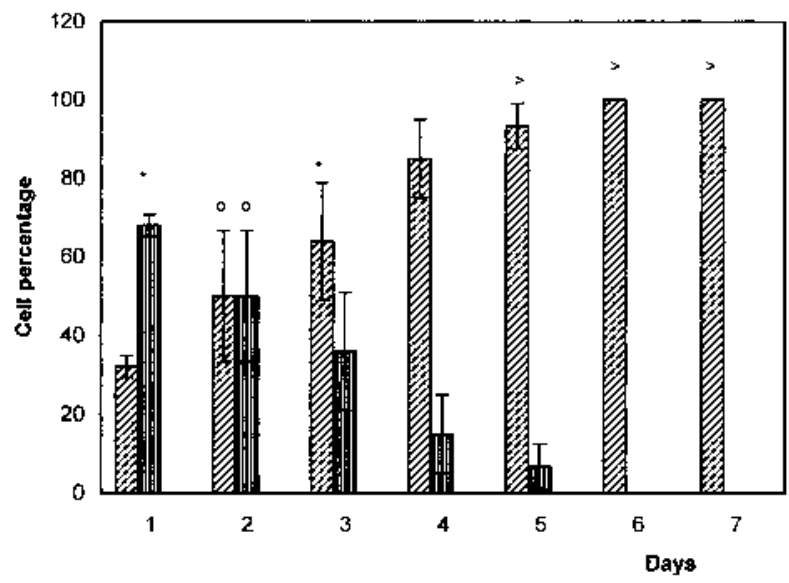

Q Surface epitheliad cells

DIntermediate cells

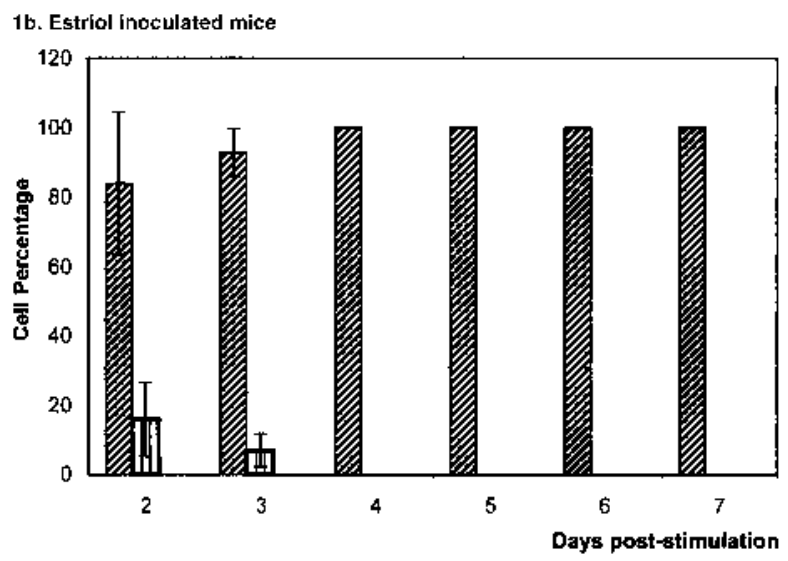

Q Surface epithelial ceds

D:Intermediate cells
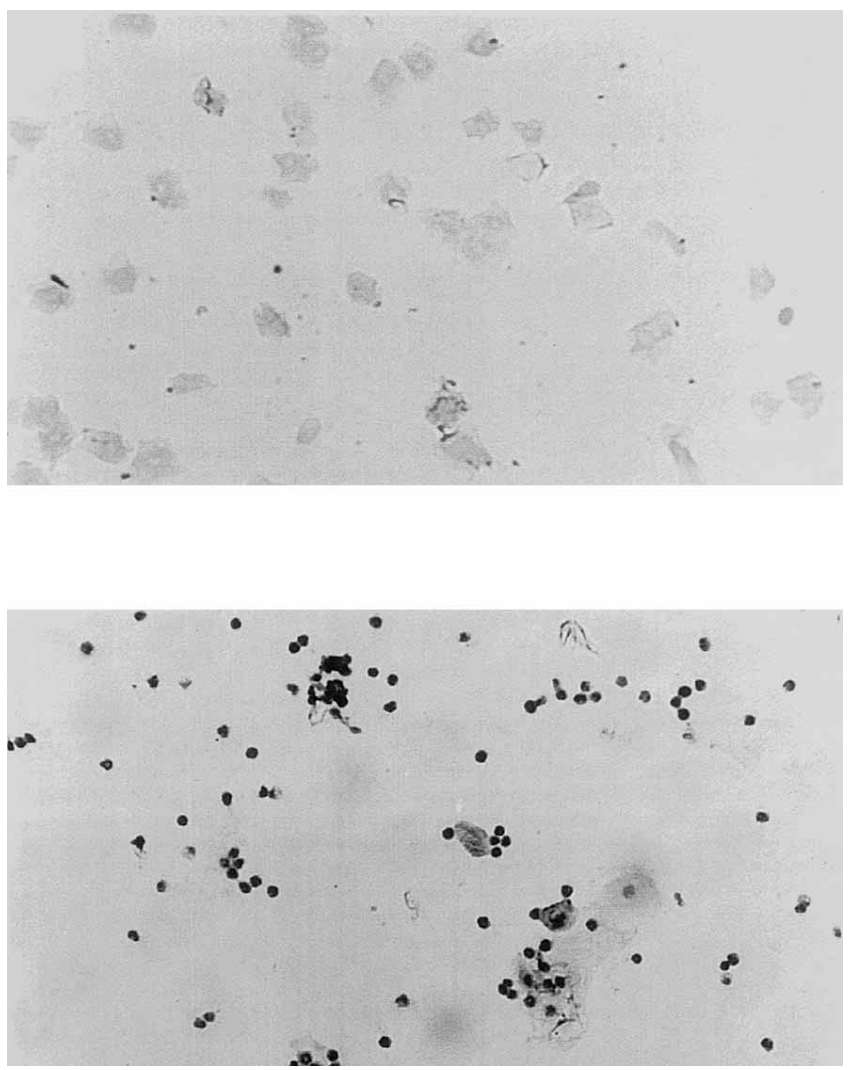

$1 d$

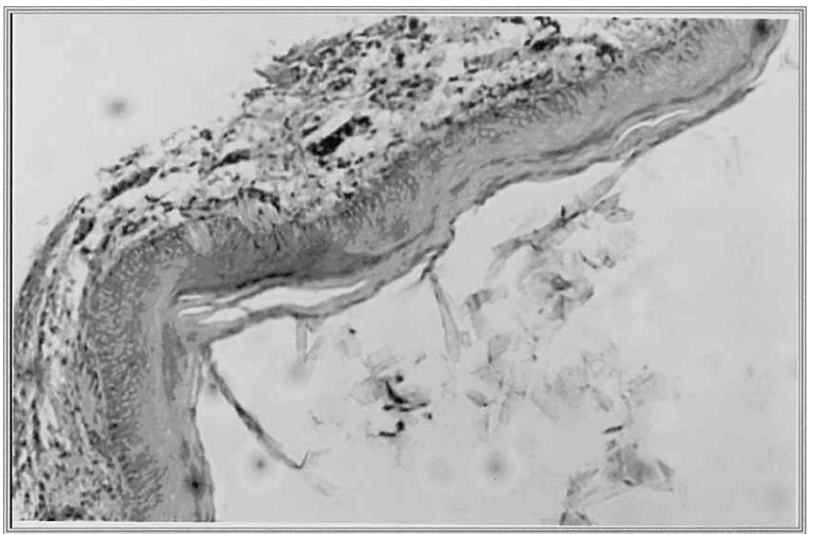

Fig. 1. Cytological and Histological Studies

Desquamated vaginal epithelial cells from control mice (Fig. 1a) and from animals inoculated intramuscularly with $\beta$-estradiol $(0.5 \mathrm{mg})$ on day 0 (Fig. 1b). The figures represent the means \pm S.D. from 3 to 5 animals.. (四) Surface epithelial cells and ( $\square$ ) Intermediate cells. The cytological results using PAP technique are shown in Fig. 1c and the histological results from vaginal slices in Fig. 1d. Details about the techniques used are described in the text.

creased to very low levels, indicating that the hormone treatment can diminish colonization of this uropathogen in all the organs. However, the number of $E$. coli in kidneys on day 2 was $10^{7} \mathrm{CFU}$ (more than $2 \log$ units above control), but decreased to numbers similar to other organs on days 3 and 6 (more than $2 \log$ units below control on the last day) (Fig. 3b).

Effect of 1 and 3 Doses of Estradiol on the Kinetics of L. fermentum Colonization in Mice Inoculated with Lactobacilli and Challenged with a Pathogen $(E$. coli $)$ When mice were treated with the hormone, one or three doses, and lactobacilli, and later challenged with $E$. coli, the number of lactobacilli in kidney on days 2 and 3 increased to values as high as those obtained in mice without pathogen challenge (Figs. $4 \mathrm{a}$ and $4 \mathrm{~b}$ ). In the remaining organs lactobacilli values were very low.

Effect of 1 and 3 Doses of Estradiol on the Kinetics of $E$. coli Colonization in Mice Inoculated with Lactobacilli and Challenged with the Pathogen In a similar experiment, inoculation of one dose of estradiol produced a decrease in the pathogen colonization when compared with control mice (not treated with hormones), and with mice treated with one dose on days 2 and 3 post challenge. On day 6 , there was a difference of $2 \log$ unit between animals treated with estradiol and E. coli, (Fig. 3a) and those protected with L. fermentum (Fig. 5a). With 3 doses of estrogen the number of pathogens in all organs of the urogenital tract decreased up to the 6th day with values lower than 101 CFU/organ (Fig. 5b). These values are slightly lower (on days 3 and 6) than those obtained in mice treated with hormones without Lactobacillus inoculation, (Fig. 3b) and also lower than control mice without hormone, but with Lactobacillus inoculation. These results indicate complementary protection against this pathogen was produced by treatment with estradiol and lactobacilli together, since on day 2, the estradiol treatment by itself allowed pathogen colonization (Fig. 3b), while no pathogen occurred in animals treated with both estradiol and Lactobacillus.

At the same time, it seems that E. coli influenced Lacto- 


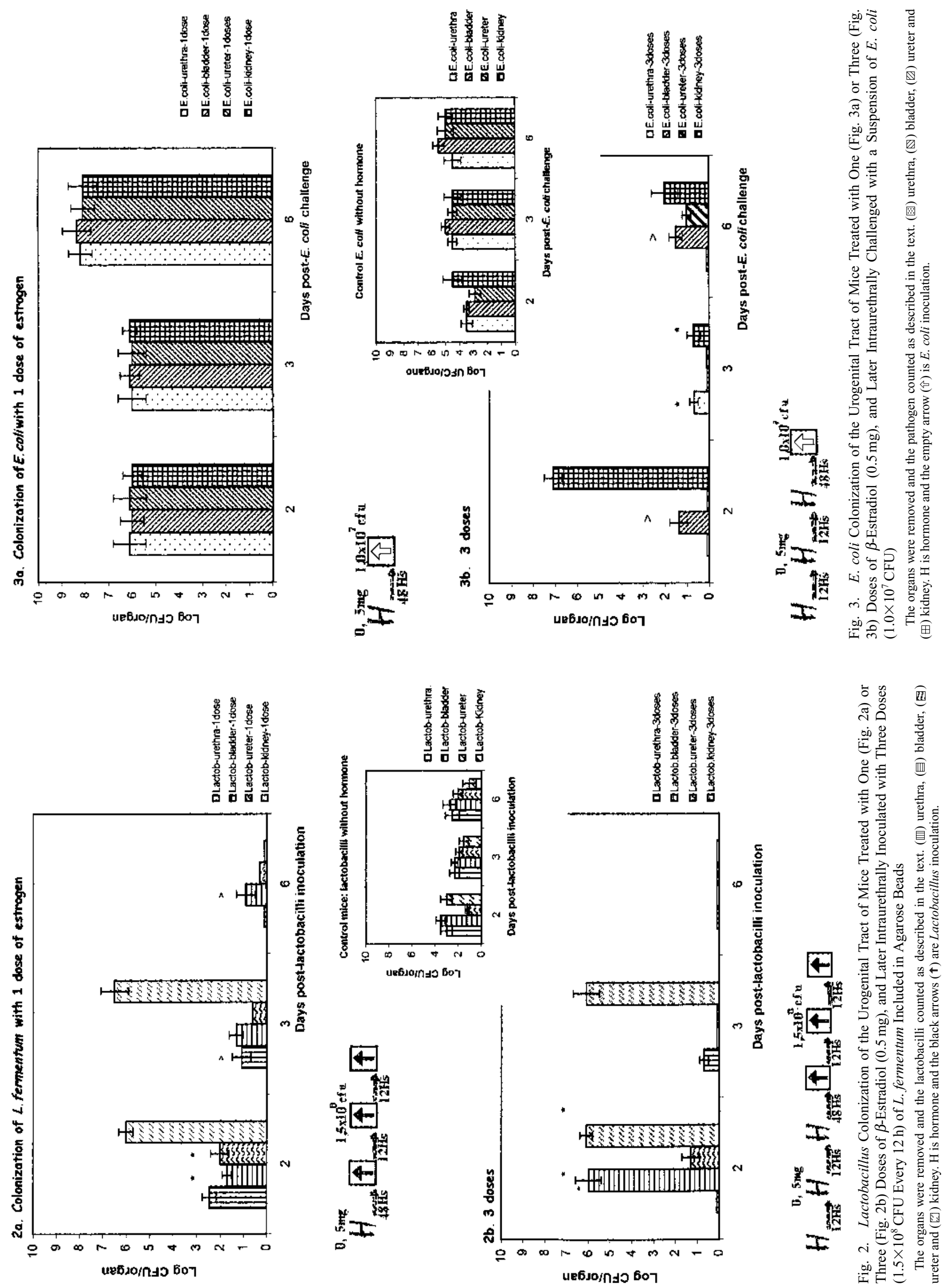



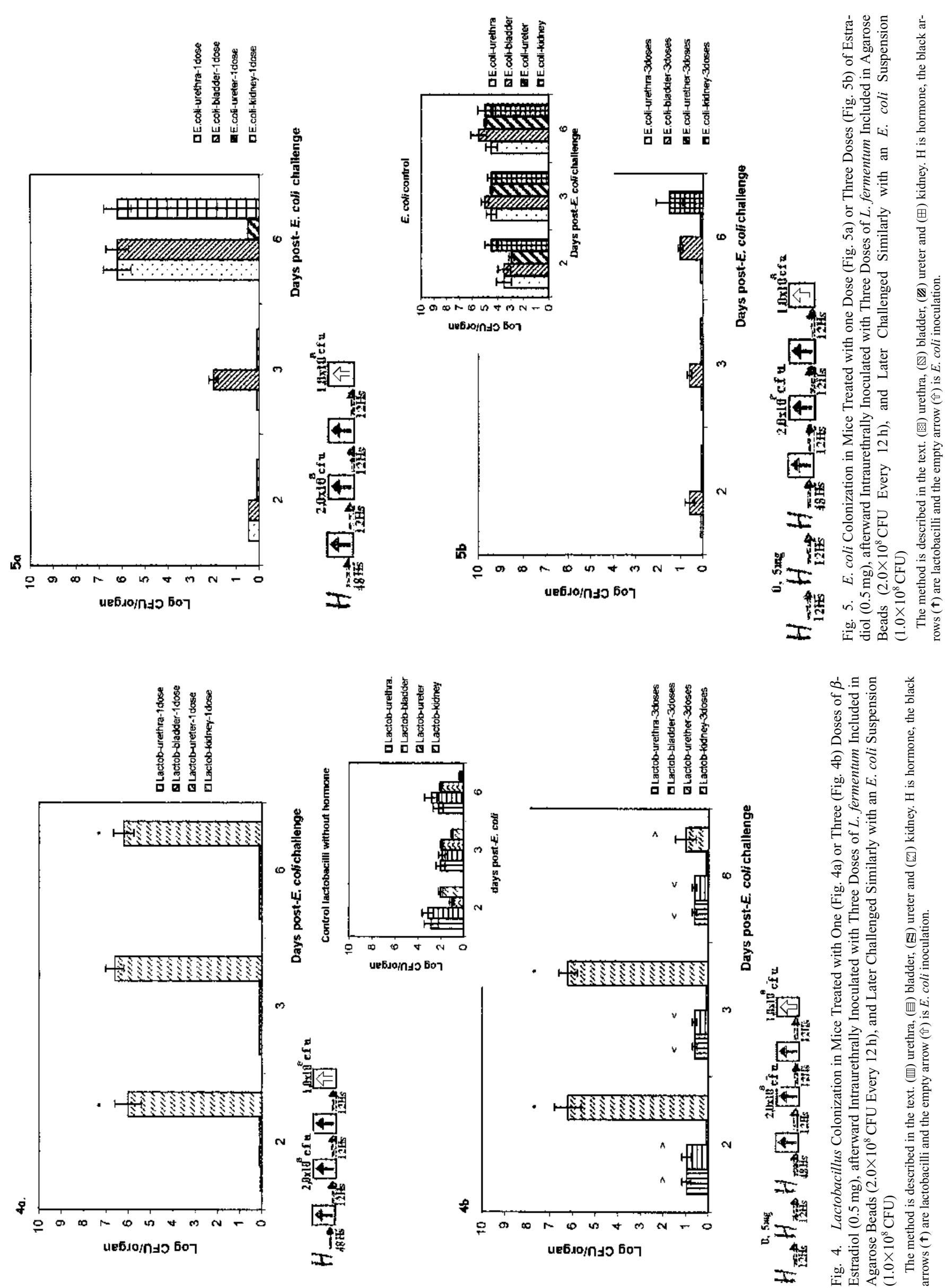

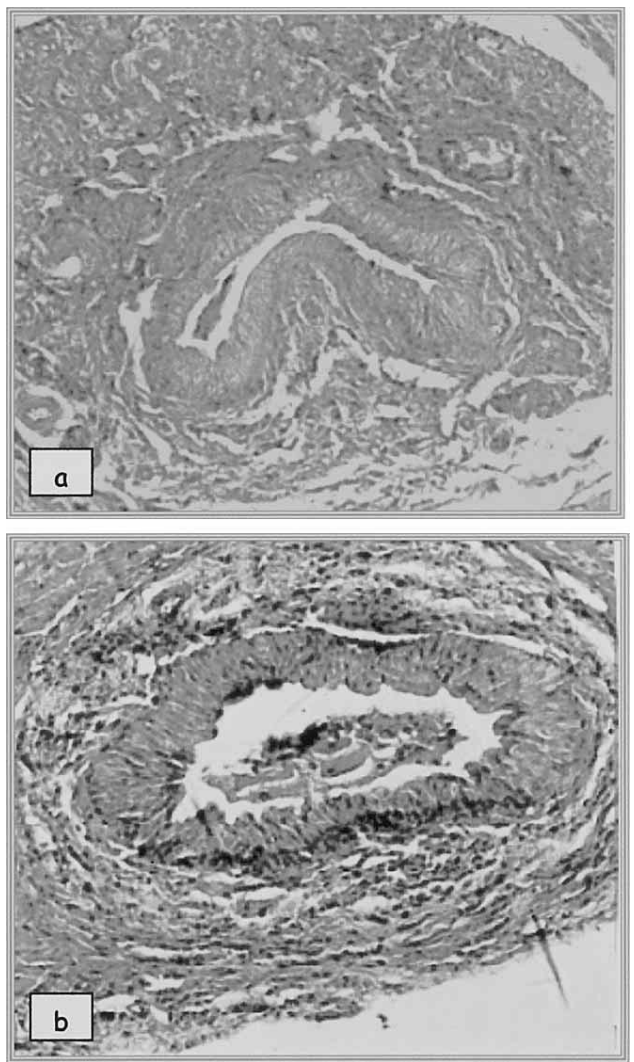

Fig. 6. Light Microscopy Images from Mouse Urethra

Animals were inoculated with $0.5 \mathrm{mg}$ estradiol (i.m.). Mice treated with $2.0 \times 10^{8}$ CFU every $12 \mathrm{~h}$ of Lactobacillus (a) and mice challenged with $1.0 \times 10^{8} \mathrm{CFU}$ of $E$. coli (b). Organs were stained with Hematoxylin-Eosin technique. Method is described in the text.

bacillus colonization. The number of Lactobacillus in Kidneys on day 6 after challenge with $E$. coli (Fig. 4a) was about 6 log units higher than without challenge (Fig. 2a). However, other organs did not show such major differences.

Histological Studies The results of the histological slices obtained through the experiments are shown in Figs. 6, 7 , and 8 . Figure 6 compares the urethra of mice treated with estrogen (Fig. 6a), and mice treated with estrogen and lactobacilli (Fig. 6b) with E. coli. A similar scheme is used to show the histological studies from bladder and kidney, in Figs. 7 and 8, respectively. Lymphocytic infiltration is observed in mice treated with $E$. coli, however lactobacilli inoculation did not produce any histological or structural changes in the urogenital tract.

\section{DISCUSSION}

The reproductive hormones produce a number of physiological changes in the host, including an increased phagocytic activity, which can influence the response to an infectious process. ${ }^{14)}$ However, modifications in carbohydrate and protein metabolism by these hormones can result in changes to the indigenous microflora of the host, due to alteration of the colonized tissues. ${ }^{15)}$ Glycogen is metabolized to glucose in the vaginal epithelia, and then converted to lactic acid as a consequence of cellular metabolism. The decrease in the vaginal $\mathrm{pH}$ in women during the reproductive years in relation to glycogen content, is supported by experiments showing that when the estrogen levels are high during this period,
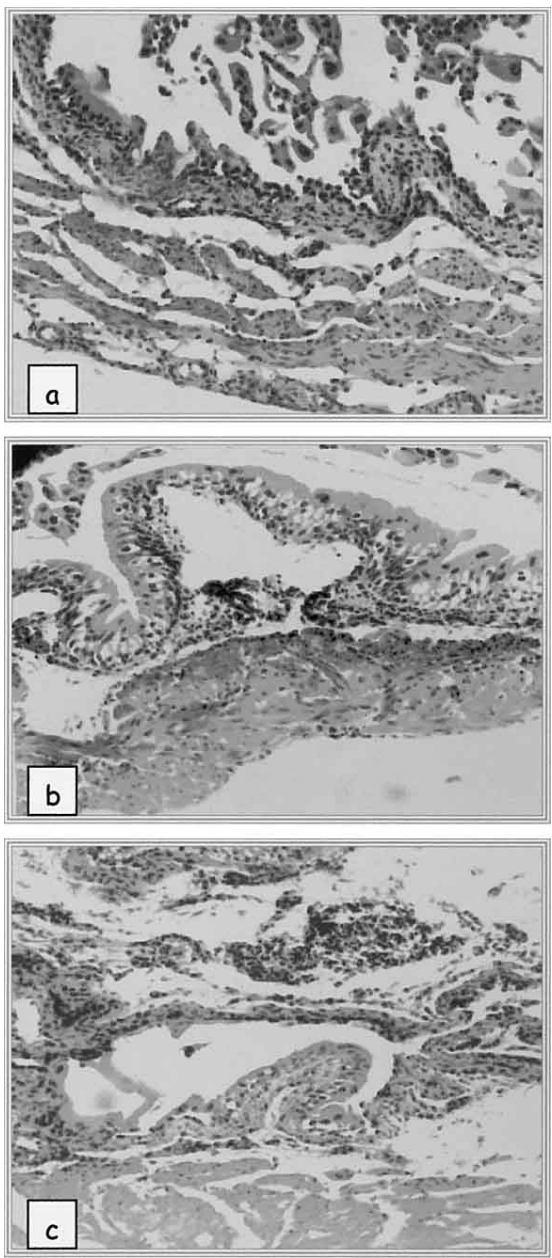

Fig. 7. Light Microscopy Images from Mouse Bladder

Animals were inoculated with $0.5 \mathrm{mg}$ estradiol (i.m.). Control mice (a), mice treated with $2.0 \times 10^{8} \mathrm{CFU}$ every $12 \mathrm{~h}$ of Lactobacillus (b) and mice challenged with $1.0 \times 10^{8}$ CFU of E. coli (c). Organs were stained with Hematoxylin-Eosin technique. Method is described in the text.

the vaginal $\mathrm{pH}$ is 5.0 to 5.5 . The vaginal epithelium is very thin in post-menopausal women, and glycogen is absent, or at very low levels. This can be the reason for vaginal $\mathrm{pH}$ modifications and a subsequent alteration of the composition of the vaginal microflora in those women. ${ }^{16}$

Some other studies have reported on modification of the normal microflora due to hormone treatment or influences: Herthelius et al. ${ }^{17)}$ have suggested that the estrogens in monkeys and humans produce changes which would favor lactobacilli colonization of the vaginal tract. Marrie et al. ${ }^{18)}$ have shown that the percentage of Lactobacillus colonization in women increases during menarche and pregnancy, and decreases after menopause.

An experimental model was set up in mice to study the protective and therapeutic effect of $L$. fermentum on urinary tract infections. ${ }^{10)}$ The main thrust was to study the effect of estradiol treatment on $L$. fermentum colonization and the $E$. coli challenge.

Before performing the experiments to study the colonization of microorganisms under estriol stimulation, the effect of estradiol on the host was tested in three different ways: First, the levels of estradiol in serum showed that the highest level was obtained 10 days after estradiol inoculation, maintaining these levels up to day 15 . Secondly, vaginal cytology 

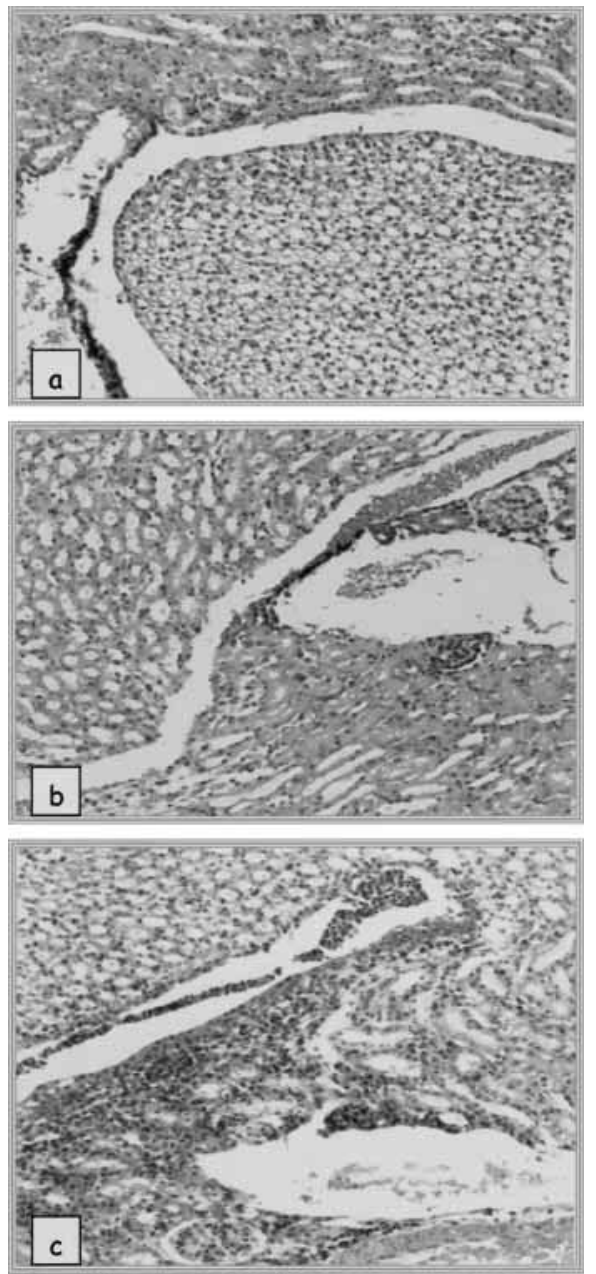

Fig. 8. Light Microscopy Images from Mouse Kidney

Animals were inoculated with $0.5 \mathrm{mg}$ estradiol (i.m.). Control mice (a), mice treated with $2.0 \times 10^{8}$ CFU every $12 \mathrm{~h}$ of Lactobacillus (b) and mice challenged with $1.0 \times 10^{8}$ CFU of E. coli (c). Organs were stained with Hematoxylin-Eosin technique. Method is described in the text.

of mice showed the clear effect of estradiol, due to the presence of upper epithelial cells without nucleus, indicating a high degree of maturation produced by estrogen administration, as seen in Figs. 1a, 1b and 1c. The number of intermediate cells was very low, showing that the differentiation process was highly influenced by estradiol. The third aspect is the keratinization of the vagina, shown in Fig. 1d, in which the difference between non-stimulated and estradiol-treated mice is reflected in the upper epithelial cells which are highly keratinized.

It must be considered that the sexual cycle in mice consists of two successive periods, called proestrous or proliferate phase, and estrous or activity period. In the proestrous phase, the vaginal epithelium begins to increase. In the smears, big round cells, rooted epithelial cells, some leucocytes and abundant secretions are observed. In the estrous period, the vaginal epithelium reaches maximal thickness, showing cornified cells of great size, some of them with picnotic nucleus, but the majority with flakes or tiles.

In the meta estrous or disintegration phase, regression of the epithelium begins because of the estrogenic deficiency. In the smears, desquamated cells from the deeper epithelium, cornified cells without nucleus and leukocytes are observed.
In the rest phase the epithelium appears thin, with very scarce epithelial cells, cornified and round, presenting a high number of leukocytes and bacteria, and much mucus.

Since the hormone treatment was effective in the experimental mice, it can be concluded that treatments with estradiol together with lactobacilli protect against the E. coli challenge.

The number of lactobacilli present in mice treated with one dose of estradiol, did not show statistically significant differences in all the organs, except for the kidney, whereas animals treated with three doses showed an increase in the number of lactobacilli in the bladder (day 2) and the kidney (days 2 and 3). E. coli was found at values higher than control mice, when mice were treated only with hormones, indicating that estradiol treatment can increase the susceptibility to pathogenic E. coli. When mice were treated with one dose of hormones and lactobacilli, the number of $E$. coli was very low on days 2 and 3 post-challenge, while their levels increased on day 6. After increasing the hormones to three doses, the number of $E$. coli was very low throughout the period studied, thus indicating protection is exerted by the simultaneous treatment of lactobacilli and hormones.

On the other hand, estradiol treatment did not produce any type of important structural histological modification other than an increased desquamation or keratinization of the cells. The effect of estriol is related to a faster maturation of the cells. The histological studies showed that lactobacilli did not produce any change in any of the organs of the urogenital tract (Figs. 6b, 7b, and 8b), while in highly infected mice, $E$. coli produced typical lymphocytic proliferation at a submucosal level, and in the bladder, as seen in Figs. 6c, 7c, and 8c.

The results obtained from the experimental model reported in this present paper are very interesting when interpolating these data to humans. An inoculation of lactobacilli ${ }^{19)}$ together with hormones in post-menopausal women with a high degree of urinary tract infections may provide a preventive to $E$. coli infections. ${ }^{20}$ )

Acknowledgements This work was partially supported by CONICET PID 385 (1998-2000) and CIUNT (D-1281998/2000) grants.

\section{REFERENCES}

1) Larsen, Bryan., Clinical Obstectrics and Gynecology, 36, 107-121 (1993).

2) Steger R. W., Hafez E. S. E., "The Human Vagina," ed. by Hafez E. S. E., Evans T. N., Amsterdam, Elsevier/North-Holland Biomedical Press, 1978, pp. 95-106.

3) Tannock G. W., Chap. 3 "Normal Microflora: An Introduction to Microbes Inhabiting the Human Body," ed. by Tannock G. W., Chapmann and Hall, London, 1995, pp. 51-60.

4) Tannock G. W. Preface. "Normal Microfiora: More than a Smell: the Complexity of the Normal Microbial," ed. by Tannock G. W. Chapman and Hall, London, 1995, pp. 1-35.

5) Nader-Macias M. E., Silva-Ruiz C., Lopez-Bocanera M. E., PesceRuiz Holgado A., Anaerobe, 2, 85-93 (1996).

6) Silva-Ruiz C., Lopez-Bocanera M. E., Nader-Macias M. E., PesceRuiz Holgado A., Biol. Pharm. Bull., 19, 88-93 (1996).

7) Nader-Macias M. E., Lopez-Bocanera M. E., Silva-Ruiz C., PesceRuiz Holgado A., Microbiol. Alim. Nutr., 10, 43-47 (1992).

8) Orskov F., Genus I., ed by "Bergey's Manual of Systematic Bacteriology," Sneath P. H. et al. Williams and Wilkins, Baltimomore, 1986.

9) Hagberg L., Jodal V., Korhonen T. K., Janson J. L., Linberg U., Svan- 
borg E. D., Inf. Immun., 31, 564-570 (1981).

10) Silva-Ruiz C., Nader-Macias M. E., Lopez-Bocanera M. E., PesceRuiz Holgado A., Microbiol. Alim. Nutr., 11, 391-397 (1993).

11) Raibaud P., Caulet M., Galpin J. V., Mocquot G., J. App. Bact., 24, 285-291 (1961).

12) Atlas of Exfoliative Cytology, Cambridge, Mass, Harvard University Press, 1954, pp. 325.

13) Rogosa M., Sharpe M. E., J. Gen. Microb., 23, 197-201, (1960).

14) Larsen B., Markovetz A. J., Galask R. P., J. Infect. Dis., 134, 486489. (1976).

15) Larsen B., Markovetz A. J., Galask R. P., Appl. and Env. Microbiol.,
34, 534-542 (1977).

16) Larsen B., Markovetz A. J., Galask R. P., Appl. Env Microbiol., 33, 556-562 (1977).

17) Herthelius M., Gorbach S. L., Mollby R., Nord C. E., Pettersson L., Winberg J., Infect. Immun., 57, 2447-2451 (1989).

18) Marrie T. J., Swantee C. A., Harten M., J. Clin. Microbiol., 11, 654659 (1980).

19) Redondo-Lopez V., Cook R. L., Sobel J. D., Rev. Infect. Dis., 12, 856-872 (1990).

20) Baerheim A., Larsen E., Digrane A., Scand. J. Prim. Health Care., 12, 239-243 (1994). 